\title{
Strengthening the Construction of Undergraduates' Scientific Research Morality in Practice Teaching
}

\author{
Wang Junbin $^{1, a}$, Wang Haifeng ${ }^{2, b}$, Ren Jian ${ }^{1, c}$, Wang Yingchao, d, and Cong Fangdi ${ }^{1, e}$ \\ ${ }^{1}$ College of Basic Sciences, Tianjin Agricultural University, Tianjin 300384, China \\ ${ }^{2}$ Center of Agricultural Analysis and Measurement, Tianjin Agricultural University, Tianjin 300384, China \\ ajunbinwang@yahoo.com, bwanghaifeng@tjau.edu.cn, ${ }^{\text {c558780250@qq.com, }{ }^{d} 38130218 @ q q . c o m,{ }^{e} 2746771}$ \\ 25@qq.com
}

Keywords: Practice teaching, scientific research morality, moral education, undergraduates.

\begin{abstract}
In recent years, academic moral anomie situation appeared frequently in the undergraduates' research training program. This reminds us that moral education of scientific research should be advanced to the undergraduate stage. In this paper, the current situation of undergraduate research of moral anomie was analyzed. Also, the reasons for this phenomenon were explored. Finally, we put forward the countermeasures to solve the problems of the moral anomie of undergraduate research from the social level, college level and student level, respectively.
\end{abstract}

\section{Introduction}

The goal of higher education is to train talents who are qualified for relevant majors or further engaged in scientific research. That requires college students not only firmly grasp the professional knowledge of this subject, but also have certain scientific research abilities. How to cultivate students' scientific research ability and make them become innovative talents in university teaching has become an important topic in the teaching reform of higher education. The important role of experimental teaching, innovative scientific research project training, laboratory opening, graduation thesis and other practical teaching in training students' scientific research quality and innovation ability is not to be replaced by any other teaching form. Through these segments, students can verify the basic theory of the course, master the basic operation technology, form independent operation ability and scientific research thinking, and lay the foundation for practical application and research work in the future.

Scientific research ethics construction is not only important for university teachers and full-time researchers, but also for undergraduate students at the learning stage. The issue of scientific research morality is fundamentally a question of moral cultivation and a fundamental criterion of human conduct. Scientific research ethics is the foundation for university students to get real talent and learning. In a sense, it is the moral bottom line for college students to do things for themselves. Strengthening the construction of undergraduates' scientific research morality is the essential rule of moral education in universities. It is an important way to cultivate innovative talents. It is the inherent need to carry forward the good style of study and the objective requirement of building a harmonious university [1].

The academic research ethics of undergraduates directly affects the future development of our academia. However, college education has always attached great importance to training undergraduates' academic research ability, but ignores the academic research ethics education that is closely related to academic activities. At present, there are cheating behaviors, such as cheating in exams, plagiarism and fraud [2]. If these phenomena are allowed to spread and pollute the academic environment of the university campus, the academic progress of our country will be hindered, and the healthy development of our scientific and cultural undertakings and the improvement of national innovation ability are even hindered. Therefore, after the transformation from "elite" to "popularization" in higher education in our country, it is imperative to strengthen the research ethics construction of undergraduates [3]. 


\section{Analysis of Current Status about Scientific Research Ethics of Undergraduates}

\subsection{Forgery or Tampering of Original Test Data.}

Some students treat science experiments with a perfunctory attitude. They do not work hard to complete the experiment tasks, so that they cannot get reasonable experimental data. In order to submit an experimental report or research paper, obtain the corresponding credits, or in order to publish a paper, the students have to "draw on" the experimental data of others, or make artificial changes and trade-offs for the original data based on their subjective desire [4].

\subsection{Plagiarize the Results of Other People's Research.}

Through the investigation of the completion of undergraduates' scientific research training program and graduation thesis in recent years, it is found that in the experiment report, research report and the writing process of graduation thesis, the participants have taken the way of cheating in order to get the ideal results. The way in which students acquire relevant data violates academic ethics and directly misappropriates data from relevant research results. Most of the graduation papers are not completed by the members of this group, many are directly copied from previous research results, and some of the students and even all the research content are fabricated [3]. This not only loses the value of scientific research itself, but also plays a counterproductive role in the cultivation of students.

\subsection{Multiple Contributions with One Manuscript.}

In order to save time or increase the probability of being used, some "smart" students will submit the same paper to two or more periodicals at the same time. This is a typical version of two or more. It is not allowed to put the same content in a paper as a new paper, or to make a new paper, or to change the same set of data into a number of papers to be published, all of which are two or more. Two or more or more copies of a manuscript will not only cause waste of resources, but also affect the reputation of the author and editorial department.

\subsection{Paper Nominal Author and Private Signature.}

It is a typical unearned immoral act that it is untrue that it is a typical unearned immoral act that is signed in a paper that he has not contributed, or as a "ride" in the current popular term. Some students think that nominal author paper is "sharing scientific research results". Some students are eager to have some articles published by means of illegally adding names to some articles. In order to improve the hit rate, the name of the instructor in the published papers is also a common phenomenon without permission. Nominal manuscripts encroach upon other people's copyright, develop academic corruption, affect reputation of the journals and bring about negative effects on assessment of academic titles.

\section{Analysis on the Causes of Undergraduates' Misconduct in Scientific Research}

\subsection{The Influence of the Social Environment.}

Multiculturalism in the period of economic and social transformation is bound to lead to multiple values. The bad atmosphere in society and impetuous uneasiness pervaded university campuses and scientific research institutions, disrupting the original quiet academic sanctuary. Under the impact and extrusion of this kind of environment, many students are at a loss in the front of multiple values, lack the standard of analysis, judgment and selection, lose the direction of value selection, lose the basic value judgment, and lead to confusion and dislocation in values, beliefs and behavior. Therefore, they are not rushing lightly and carelessly in scientific research ethics. They are indulging themselves and following the trend.

\subsection{The Weakening of Moral Education in Scientific Research.}

As a regular and specialized educational base, colleges and universities not only bear the task of imparting knowledge, but also as the cradle of higher talents, it should be the place to cultivate 
wisdom and cultivate morality, and should take full account of the specific education of scientific research morality and academic responsibility in the content of inheritance, reality and practicality. Abandoning the moral education of academic research and ignoring the moral education of university students, it is not a complete and scientific of university moral education [5].

\subsection{Lack of Understanding of Scientific Research Norms.}

The correct understanding of scientific research norms is the most basic premise and basis for undergraduates to abide by scientific research norms. Because undergraduates do not have a clear understanding of the norms of scientific research, they do not know what the concept of scientific research is. They also do not know what copy is, what plagiarism is, what a reasonable reference is, and how to correctly quote other people's views according to the standard of scientific research and so on [6]. The lack of basic scientific research morality aggravates the overflow of the phenomenon of the moral anomie of the undergraduates.

\section{Countermeasures to Solve the Moral Anomie of Undergraduates}

\subsection{Promoting the Innovation of the Training System of Undergraduates.}

The students' learning goals are different. Some want to engage in exploratory activities in the future. Some only want to be qualified workers in the field of occupation. The former needs training in scientific research and the latter is not necessary. Therefore, it is not appropriate for all undergraduates to do graduation thesis and participate in scientific research. Forcing students who do not want to and cannot participate in scientific research will inevitably lead to plagiarism and other behaviors. Let those students who are good at study and have the desire to engage in scientific research get more and better support and guidance, so as to make the limited resources more effective.

\subsection{Strengthening Undergraduates' Ideological and Moral Education and Building a Good Style of Study.}

If the moral education of the university is only to carry out the ideological and political moral education, it is difficult to reflect the essential nature of its own, not enough to distinguish between the moral educations of other types of schools. The implementation of moral education in academic research is the essential requirement of moral education in universities. Through continuous learning style construction, create a good atmosphere for teaching and research. Although colleges and universities cannot change the whole social atmosphere, we can create a good campus environment to reduce the interference.

\subsection{Cultivating Academic Morality and Honesty Consciousness in Practice Teaching.}

In order to develop students' sense of responsibility for scientific research, they should have a good knowledge of the history tradition and the ethical problems that are involved in this field. Teachers should guide students how to observe experimental phenomena and require students to draw data tables, and record experimental data objectively. It is not allowed to fabricate data, exaggerate facts, modify data and plagiarize others' research results. The curriculum and assessment mechanism of intellectual property knowledge should be popularized among students. By learning scientific research standards and relevant laws and regulations, the students should enhance the awareness of intellectual property rights protection.

\section{Conclusion}

Since the 21st century, human beings face various crises. So, people are calling for integration of scientific freedom and ethics and emphasize the social moral responsibility of science and technology workers. Therefore, it is extremely urgent to educate undergraduates about science and technology ethics. Thus we have to start from carrying out system innovations, creating a healthy environment for scientific research. Also, we should promote scientific morality, create a regulation 
system and improve the moral integrity of researchers. Thus not only the external forces are needed to control the moral trend, but also self-discipline of the researchers should be achieved.

\section{Acknowledgements}

This work was financially supported by the university teacher education reform and innovation guidance development projects of TJAU (20170402 and 20171009).

\section{References}

[1] M.A. Henning, S. Ram, P. Malpas, R. Sisley, A. Thompson and S.J. Hawken: J. Med. Ethics Vol. 40 (2014), p. 702-709.

[2] L.F. Deng, Y.Y. Long, X.Y. Fu: Fudan. Educ. Forum Vol. 15 (2017), p. 88-94 (in Chinese).

[3] R. Comas-Forgas, J. Sureda-Negre: J. Academic. Ethics Vol. 8 (2010), p. 217-232.

[4] M.S. Anderson, N.H. Steneck: Semin. Urol. Oncol Vol. 29 (2011), p. 90-94.

[5] R. Jurdi, H.S. Hage, H.P.H. Chow: Can. J. Higher. Educ Vol. 41 (2011), p. 1-35.

[6] Y.L. He, D. Yang, C.L. Tian, D.Y. Ding: J. Higher. Educ. Res Vol. 33 (2010), p. 86-88 (in Chinese). 